\title{
EL "HOMBRE QUE VIENE DE LO ALTO". ELITISMO Y MARGINACIÓN EN LA ANTROPOLOGÍA VALENTINIANA
}

\section{JUAN CARLOS ALBY*}

Una de las discusiones más relevantes entre los eclesiásticos y los gnósticos del siglo II, se suscitó en torno a la concepción del hombre. Entre los discípulos de Valentín' ${ }^{1}$ quien dio origen a la corriente gnóstica más

* Profesor de la Universidad Nacional del Litoral y Universidad Católica de Santa Fe (jcalby@hotmail.com).

1 Valentín nació en Egipto, se educó en Alejandría y enseñó en Roma entre el 135 y el 160 d.C. Fue el único gnóstico que tuvo ciertos discípulos conocidos por sus nombres, entre los cuales se destacan Tolomeo y Marco, quienes fueron a su vez creadores de escuelas y maestros de sus propias versiones de la doctrina valentiniana. El principio teórico del valentinismo promovía el desarrollo de ideas libres por parte de sus discípulos, a punto tal que nuestro conocimiento de la doctrina proviene más de las elaboraciones posteriores de sus seguidores de la segunda generación, que de las enseñanzas de Valentín de las cuales es poco lo que se conserva. El Eivangelio de la Verdad, hallado en lengua copta y del cual tenemos hoy versión castellana (en: Piñeiro Antonio, Montserrat Torrents José y García Bazán Francisco, Textos gnósticos, Biblioteca de Nag-Hammadi, Trotta, Madrid, 1999, Vol. II: Evangelios, bechos, cartas, pp. 140-161), puede haber sido escrito por el mismo Valentín o por un discípulo muy cercano. Su escuela fue una de las más fecundas, por la intensa teorización caracterizada por la libertad y la gran riqueza de su diferenciación doctrinal. Una prueba de ello la tenemos en el hecho de que, sólo en lo que respecta al desarrollo de la doctrina del Pléroma (interioridad de la esfera de lo divino, plenitud del ser de Dios), disponemos de al menos siete versiones diferentes entre las de Ireneo, Hipólito, Epifanio y los Excerpta ex Theodoto de Clemente de Alejandría, sin contar la de Marco apodado "el Mago". La considerable diferencia entre estas versiones, revela una notable independencia de pensamiento. Como consecuencia de fuertes controversias teóricas, la escuela fue dividida en varias ramas, de las cuales se conoce una anatolia por medio de los Excerpta ex Theodoto y otra itálica, más documentada, a la que perteneció Tolomeo, tal vez el más lúcido constructor de sistemas entre los 
sofisticada por su elaborada doctrina, se formuló una antropología centrada en una especie particular de hombre investido por la iluminación de la Gnosis, en virtud de lo cual se lo denominó pneumático o espiritual. En la jerarquía antropológica de los gnósticos, este hombre "espiritual" ocupaba el sitial más elevado; por debajo de él seguían el "psíquico" o racional, intermedio entre el hombre pneumático y la especie de hombre cualitativamente inferior: el býlico o material.

Estas categorías de "hombre" obedecían a una distinción en la naturaleza de la "sustancia" de la que estaban hechos, la cual a su vez decidía el destino dispar de cada uno de los tres linajes: el "espiritual" estaba llamado a la salvación independientemente de sus obras; el "psíquico" podía acercarse a uno u otro extremo de la jerarquía antropológica según el ejercicio libre y racional de su psyché; mientras que el "material" estaba predestinado a la condenación y aniquilación en virtud de su naturaleza corrompida, más allá de la calidad moral de sus acciones.

A fin de mostrar las consecuencias de esta peculiar doctrina antropológica, expondremos en primer lugar su fundamentación desde ciertas especulaciones cosmológicas ligadas al mito gnóstico; seguidamente nos detendremos en el análisis de la condición histórica del hombre considerado por los gnósticos como "espiritual", para dar paso finalmente a la reacción de Ireneo de Lyon, quien sobresale entre los eclesiásticos oponiendo una antropología bíblica despojada de elementos míticos y más acorde con las nociones de libertad y responsabilidad.

\section{Fundamentación cosmológica de la antropología valentiniana}

El mito valentiniano sostiene que, como fruto de una pasión acaecida en el seno de la interioridad divina o Pléroma, se produjo la expulsión de una materia amorfa hacia fuera de la plenitud de Dios. Esa pasión fue suscitada

gnósticos. Ireneo caracterizó de modo pintoresco a los valentinianos en un texto de Adversus baereses (en adelante: Adv. baer:) I, 18,5: "Cada uno de ellos inventa algo todos los días, y ninguno es considerado perfecto si no es capaz de producir estas novedades". Cfr. Jonas, Hans, I a religión gnóstica. El mensaje del Dios extraño y' los comienzos del cristianismo. Trad. Menchu Rodríguez, 2a . ed., Siruela, Madrid, 1962, p. 205. 
por la ignorancia de una hipóstasis divina llamada Sopbia, quien había sido concebida como un agente o ayudante de Dios en la creación del mundo y personificaba el aspecto falible de Dios.

Deseando conocer al Padre Desconocido o Dios Ignoto, se hizo protagonista de una tragedia cósmica. De este modo, el mito gnóstico eleva la ignorancia -así como también su opuesto, el conocimiento-, a un nivel ontológico, como principios de existencia objetiva y no sólo de experiencia subjetiva e individual. Esta ignorancia se convierte así en el principio generador del mundo infrapleromático, causa principal de la defección de la sustancia amorfa "extramuros" de la plenitud divina. De esta manera, la materia resulta concebida como una "función" más que como una sustancia; es la expresión externa y coagulada de su principio fundante: la ignorancia; vale decir, el resultado residual de un proceso de introspección en estado de deterioro, la forma oscura y errante de su opuesto, el Pneuma pleromático, que es la única fuente suprema con la cual esa materia se relaciona a través de numerosos estados intermedios llamados eones. Del mismo modo, su causa generatriz, la ignorancia, es la forma oscura de su opuesto: el conocimiento o Gnosis, única posibilidad de retorno al Pléroma.

Ese conocimiento es la clave de la soteriología gnóstica, único medio válido para la salvación, que se convierte en un acontecimiento cósmico en cada individuo que es iluminado, pero a la vez, lo trasciende restaurando la divinidad deteriorada.

Ahora bien, sostenían los valentinianos que, a partir de la materia amorfa, se escindieron tres sustancias: una "espiritual" femenina llamada Sopbia, madre de los hombres "espirituales" o pneumáticos, otra "racional", que dio origen al Demiurgo Yabiveh, quien a su vez constituye el origen de $\mathbf{b}$ Hebdómada ${ }^{2}$ y de los hombres "racionales", llamados también "animales" o

2 Se refiere a los "Siete" dioses planetarios que dominan las esferas cósmicas. La cosmología gnóstica consideraba al universo como una inmensa prisión cósmica, cuya "mazmorra" más profunda era la tierra, una especie de celda sepultada que servía de escenario al desenvolvimiento del drama humano. Esa celda estaba circundada por esferas cósmicas concéntricas: las siete esferas del los planetas rodeadas por la octava esfera, la de las estrellas fijas. En el sistema de Basílides, otro célebre gnóstico, las esferas alcanzan a 365. Las siete esferas planetarias están 
psýcbicos, y, en tercer lugar, una naturaleza býlica que a su vez se disoció, por un lado, en "espiritual" o diabólica, origen de los ángeles malignos; por otro, en "irracional", origen de los hombres býlicos, "materiales" o irracionales y de las almas de los animales, y finalmente, en una naturaleza býlica "pura", origen de los cuatro elementos físicos, a saber: aire, tierra, fuego y agua 3 .

Como puede apreciarse, hay un determinismo naturalista en el origen de cada tipo humano: el hombre "espiritual" surge de una sustancia emanada de Sophía y, aunque cualitativamente imperfecto y destituido de la Gnosis, es hijo natural de Dios y llamado en su sustancia a la perfección de la Gnosis, a pesar de que en su origen resulta incapaz de ella; esta sustancia es más elevada en dignidad que la que da origen a los hombres "racionales", ya que estos proceden del Demiurgo, e infinitamente superior a la que sirve de

dominadas por fuerzas demoníacas activas denominadas "arcontes", cada una de las cuales se constituye en un guardián de cada esfera cósmica. Estas divinidades fueron tomadas por los gnósticos del panteón babilónico, y en algunos casos recibían nombres con los cuales el Antiguo Testamento identifica a Dios: Iao, Sabaoth, Adonai, Elobim, El-Sbaddai. Esta transposición de nombres de una divinidad única y superior a una pluralidad de seres demoníacos inferiores, manifiesta claramente el desprecio que los gnósticos sentían por la tradición judía. Pero el rasgo antisemita alcanza su consumación en la identificación del demiurgo con el Yabweb del Antiguo Testamento. La peculiaridad de esta arquitectura celeste radica en que de ese modo queda garantizada la separación del hombre de lo que está "más allá", tanto por las limitaciones espaciales que impone la disposición de las esferas, como por la tiranía opresiva de los arcontes, que a la vez que obstaculizan a las almas en su ascenso hacia el Padre Desconocido confinándolas a la tierra, dispensan el destino universal que recibe el nombre de beimarméne. En este concepto, los estoicos veían el aspecto práctico de la barmonia, hallada por los pitagóricos en el orden astral según las proporciones de la escala musical, y que es a la vez la acción que afecta el devenir de la vida terrenal de los hombres. Creían que los movimientos de los astros eran producidos por el lógos cósmico inmanente al mundo. Claro que, en un sistema monista como el de la filosofía del Portal, la heimarméne era a la vez prónoia, es decir, destino y providencia divina al mismo tiempo. La aceptación voluntaria de este destino es lo que distingue al hombre sabio del que no lo es, ya que el primero soporta el destino individual como la parte que hay que pagar para contribuir a la armonía del todo.

${ }^{3}$ Cfr. Adv. baer. I,5,1. 
matriz a los hombres "materiales".

El hombre psýchico o "racional" es intermedio en dignidad y naturaleza, equidistante del hombre pneumático o "espiritual", y del hombre býlico o "material", entre el polo respectivamente más encumbrado y el más degradado de la escala antropológica.

Estas tres definiciones de "hombre" orientaron las preferencias de los teólogos más destacados de los siglos II y III. Los valentinianos pusieron el acento en el hombre espiritual, caracterizado por el pneuma; Orígenes y Clemente de Alejandría, en quienes se advierte una gnosis moderada o intermedia entre la valentiniana y la ortodoxia cristiana, volcaron sus preferencias hacia el hombre racional o psíquico, caracterizado por la psyché; por su parte, Ireneo de Lyon se ocupó del hombre "plasmado", de carne y hueso, caracterizado por el sôma.

\section{Condición histórica del hombre "espiritual"}

La antropología valentiniana fue mucho más elaborada que la de sus predecesores, recayendo todo el peso de su especulación teórica sobre la cuestión del hombre "espiritual".

Conscientes de la aporía que surgía de considerar que Dios había creado al hombre en estado de imperfección ${ }^{4}$, dan inicio a la Economía de la

4 Esta aporía es denunciada al menos en dos ocasiones. Una, en la tesis del marcionita Apeles, quien en el tomo 38 de sus Silogismos sostiene que, si el árbol de la vida tiene más eficacia para la vida que el soplo de Dios, según parece desprenderse de la lectura del Génesis, el hombre hecho por Dios "imperfecto", lograría por medios propios lo que Dios le otorgó; en consecuencia, el hombre haría más que Dios. Para resolver la paradoja, Apeles niega la inspiración divina del Génesis, la divinidad del demiurgo del Génesis, y, por lo tanto, la credibilidad misma de la noticia de Moisés. El Dios Bueno de Platón (Iímeo 3,29e) no tiene envidia, de modo que nunca hubiera expulsado al hombre del paraíso por envidia de la vida, así como tampoco le hubiera negado la perfección desde el principio. Sobre esta cita de Platón, Ireneo tiene algo que decir: "Platón, en comparación con éstos (los marcionitas), es más religioso. Confesó a Dios justo y’ bueno, con poder universal y con oficio de juzgar. En efecto, escribe: 'Dios, como dice la antigua tradición, tiene 
Salvación con la aparición del hombre pneumático "no perfecto".

Si los hombres "espirituales" surgieran a la existencia an perfectos como el Dios Bueno, "hombre" y "Dios" serían equivalentes. Sin embargo, resultaría compatible con la infinita bondad del Dios Bueno engendrar una infinidad de hijos destinados a deificarse en un mundo no divino, hecho por el Demiurgo, para lo cual será necesario elevar la sustancia creada de lo imperfecto a lo perfecto, a la altura de lo Increado.

Por esta vía, los valentinianos logran aproximar los dos extremos incompatibles, hombre y Dios, hacia la unidad personal en comunión con el Unigénito.

Esto, sin embargo, no se produce sino a través de ciertas etapas. En un primer paso, establecen la existencia de un Antbropos perfecto, Hombre pneuma hecho directamente por el Dios Bueno a través de dos fases: una interior en la que es concebido como Unigénito en el seno del Padre, y otra exterior, nacido como Cristo, fuera del Padre.

en su mano el inicio, el medio y el fin de todas las cosas, en todo obra rectamente, envolviendo todo por naturaleza. Siempre lo sigue la justicia vengadora de cuantos violan la ley divina' (Lejes IV). En otro lugar muestra al Creador y Demiurgo del universo, en toda su bondad: 'En el que es bueno, jamás brota ninguna envidia de nadie' (Timeo 3,29e). Pone la bondad de Dios como principio y origen de la creación del mundo, no 'la ignorancia' ni 'los lamentos y clamores de la Madre (Sophía), ni 'otro Dios y Padre"'. (Adv. haer III,25,5). Y en otro lugar: "Por este motivo 'lo echó del Paraíso' y lo alejó ‘del árbol de la vida' (Gén.3,23-24). No es que Dios sintiese celos por el árbol de la vida, como algunos se atreven a opinar; sino que fue acto de misericordia alejarlo para que no siguiese transgrediendo, a fin de que su pecado no estuviese en él para siempre como un mal insaciable y sin remedio. De este modo le impidió seguir transgrediendo el mandato, le impuso la muerte y marcó un límite al pecado al ponerle a él un término en la tierra mediante la disolución de la carne. De esta manera el hombre, al morir, dejaría de vivir para el pecado y comenzaría a vivir para Dios." (Adv. baer. III,26,3).

Clemente de Alejandría es el otro que denuncia la misma aporía entre los valentinianos: “¿Fue Adán plasmado perfecto o imperfecto? Si imperfecto, ¿cómo es imperfecta la obra de un Dios perfecto, sobre todo, el hombre? Si perfecto, ¿Cómo falta a los mandamientos de Dios?" (Strómata, VI, 12, 96). 
Este Anthropos, en comunión con el Pneuma masculino, es perfecto y no requiere proceso alguno de deificación. Los valentinianos lo llaman "el Varón" (Anér), en contraposición a "la Hembra" (théleia) o Sophia, caracterizada por el pneuma femenino. Queda así establecida una diferencia cualitativa entre el Pneuma perfecto masculino del Ántbropos, y el pneuma imperfecto femenino del Espíritu personal.

En una segunda instancia, los valentinianos explican cómo se introdujo en la historia el pneuma "no perfecto", comenzando por Adán y siguiendo por la línea de Seth, responsable de la propagación de la simiente "espiritual" en el género humano.

Asimismo, consideraban a Caín como el exponente del hombre býlico, gobernado por las leyes irracionales de la materia, y a Abel como el iniciador del linaje de los hombres psýchicos, consustanciales con el Demiurgo Yabweh, Creador y Legislador ${ }^{5}$.

Atribuyen, entonces, al pneuma de Sopbia la causa de la introducción en el mundo del pneuma "no perfecto", eximiendo de tal responsabilidad al Antbropos perfecto.

Si bien el pneuma "no perfecto" ingresa en la historia humana sujeto a las leyes de la materia y del alma racional, ignorante de su propia condición y en régimen de mortalidad, no obstante, está destinado por naturaleza a la "visión de Dios", término con el que se designaba la consumación perfecta y escatológica de todo hombre considerado individualmente. Por lo tanto, para superar ese régimen de ignorancia y muerte, era preciso que el hombre pneuma madurara en este mundo para pasar al estadio bienaventurado de la Gnosis.

$\mathrm{Al}$ asignarle un desarrollo histórico al hombre pneuma, desde la aparición en el mundo como pneuma "no perfecto" hasta su conversión en "perfecto" mediante la Gnosis, los valentinianos resolvieron la aporía

${ }^{5}$ Resulta curioso que los valentinianos designen a Abel como el que inaugura el linaje racional o psíquico, excepto que se interprete como arquetipo del hombre psíquico, ya que por su homicidio prematuro es dudoso que Abel haya dejado descendencia; al menos, es lo que da a entender la noticia del Génesis que, en cambio, describe detalladamente tanto la descendencia de Caín como la de Seth. 
mencionada: no los creó perfectos desde el principio, a pesar de estar en los planes del Dios Bueno la consumación del hombre pneumático al final de la historia de la salvación, para multiplicar a sus hijos en Iglesia, según el arquetipo del Ánthropos perfecto.

Las etapas de ese desarrollo del hombre pneuma desde su aparición en el mundo hasta su retorno a Dios, alcanzado en su ingreso al Pléroma, se da en dos líneas: una individual, que interesa a los hombres en tanto singulares, y otra eclesial, que los afecta como Iglesia.

La línea individual se desarrolla en una historia determinada por el Salvador para cada individuo, que va desde el hombre imperfecto al perfecto, disciplina ndo el pneuma según las leyes de la materia y de la psyché. En cambio, la fase posterior a la Gnosis, de sesgo eclesial, ocurre fuera de la historia y se rige por las leyes del Espíritu masculino.

De este modo las fases del desarrollo individual quedan delineadas como sigue:

a) Antes de la Gnosis: el hombre pneuma, cualitativamente imperfecto en su condición original, no está dotado de las propiedades del Pneuma masculino de Dios y de su Hijo. Por lo tanto, nace en este mundo sujeto a las limitaciones del hombre bylé y del hombre psyché, con quienes convive destituido de la Gnosis, ligado a las leyes de la materia irracional y de la psyché racional. El pneuma femenino de Sophia lo había insertado en el interior del individuo material y psíquico, "escondido y envuelto como en doble vaina"6 en el hombre býlico irracional y en el psýchico racional, hasta el momento de recibir la Gnosis. Hasta tanto, el pneuma sumergido en las sucesivas "envolturas" de la psycbé y de la býle convive con ambos en plena inconsciencia de sí, y la ética del hombre "espiritual" no difiere de la de los býlicos y psýcbicos. Esta primera etapa preliminar a la Gnosis puede subdividirse a su vez en dos. Hasta los siete años, según los valentinianos, experimenta un crecimiento de acuerdo con las pautas del hombre býlico, sujeto a sus leyes hasta adquirir el uso de razón. Pero a partir de los siete, crece según el desarrollo del hombre psýchico bajo la disciplina del Demiurgo, hasta la madurez racional con absoluto dominio de las pasiones.

${ }^{6}$ Cfr. Orbe Antonio, Espiritualidad de San Ireneo, Universidad Gregoriana, Roma, 1989, p. 12. 
b) Después de la Gnosis: se transforma en hombre pneuma "perfecto", superando el régimen de ignorancia de sí y adquiriendo conciencia de su origen divino. La Gnosis es obra de Cristo, quien "masculiniza" el pneuma humano otorgándole las propiedades del Unigénito.

Sólo a partir del Nuevo Testamento, Cristo en su venida otorga la Gnosis al hombre pneumático, y este acontecimiento tiene lugar para cada individuo en un instante determinado, como un don gratuito conferido por el Salvador. Precisamente por tratarse de un don gratuito y repentino, no necesita del crecimiento a lo largo de la historia al que está sometido el hombre antes de recibir ese don que se distribuye a cada uno con la misma calidad y medida, incorporando por igual a todos los "espirituales" al régimen salvífico.

En consecuencia, si la Gnosis fue dada en la venida de Cristo, es fácil deducir que ningún hombre pneumático del Antiguo Testamento logró la perfección; al morir, pasaban como psyché al Hades, particularmente a una "división" del mismo conocida como "Seno de Abrahám", donde esperaban la definitiva salvación.

La primera etapa de la fase individual, previa a la Gnosis, con sus dos sub-etapas, es lenta y preparatoria, mostrando un progreso de býlico a psýcbico; es una etapa histórica, ocurre en el tiempo y en el espacio. Por su parte, lo que sigue a la recepción de la Gnosis ya no es histórico, pues introduce al individuo en la eternidad.

Resumiendo, el hombre "espiritual", a partir del Nuevo Testamento o de la venida de Cristo, pasa por las mismas etapas que atravesó el género humano en el Antiguo Testamento a partir de Adán, caracterizadas por un arduo proceso de ignorancia, creciendo hacia su maduración histórica, hasta recibir la repentina Iluminación, es decir, la Gnosis en el caso del individuo, y el Nuevo Testamento, en el de la humanidad toda. Es una especie de historia de la salvación compendiada en escala individual.

En cuanto a la fase eclesial del proceso, ésta es también de carácter suprahistórico, e incluye dos momentos que los valentinianos describían 
como el "banquete nupcial en la Ogdóada" en la consumación de los tiempos, y el "ingreso al tálamo", Pléroma o seno de Dios, por parte de los hombres y ángeles "espirituales", para consumar eclesialmente el matrimonio "ángel/hombre" iniciado individualmente ya en este mundo, al momento de recibir la Gnosis. Nos encontramos aquí en plena escatología gnóstica, la cual se vuelve problemática a la luz del siguiente planteo: si la Gnosis determina la perfección repentina del hombre "espiritual", ¿qué clase de conocimiento se le otorga al individuo en virtud de tal fenómeno? Posiblemente un conocimiento a priori de sí, del ángel, del Salvador y del Dios Espíritu. Pero esto no sería compatible con la escatología gnóstica ya que, según Tolomeo, los "espirituales" que en virtud de la Gnosis consuman el matrimonio para siempre con los ángeles en la perfección divina (syntéleia), aparecen separados de ellos mientras permanecen aún personalmente unidos con sus respectivas psychés, para abandonarlas en la Ogdóada sólo después del banquete nupcial e ingresar como "espíritus puros" en el Pléroma junto a los espíritus angélicos, a fin de consumar el definitivo matrimonio con ellos. Ante esta dificultad, se suelen presentar dos explicaciones. La primera sostiene que, a partir de la recepción de la Gnosis, el hombre "espiritual" se salva ya en este mundo, adquiriendo el conocimiento de sí, de su ángel, del Salvador y de Dios. El pneuma humano unido al angélico, se liga de modo indivisible al del Hijo y al del Padre. El banquete nupcial, primer acto de la syntéleia todavía separado del espíritu angélico, y el posterior ingreso al tálamo o Pléroma para el matrimonio con él, expresan en lenguaje mítico lo que ya

\footnotetext{
7 Según lo que Ireneo de Lyon describe en el libro I del $A d v$. baer., más precisamente desde el I,1,1 al I,8,4 con respecto a las enseñanzas de Tolomeo, un destacado discípulo de Valentín, el sistema valentiniano ratificó los detalles principales del mito gnóstico, según el cual, en el origen de todo se encuentra un Primer Principio, Dios Supremo, Abismo, inengendrado y en reposo profundo. Con él coexiste el Pensamiento, llamado también Silencio y Gracia. De esta pareja, que en realidad es un solo ser, surgen emisiones sucesivas, pares de eones o syzygias (parejas): Inteligencia, Verdad, Lógos, Vida, Hombre, Iglesia; "en vista de la gloria del Padre". Esta primera emanación con el Principio, forma la Ogdóada (por las ocho entidades), de la que surgirán luego otras emisiones. Con algunas variaciones, este mito también se describe en el informe de Hipólito, Elenchos VI,29,1-36,4. Cfr. García Bazán Francisco, Gnosis. Ia esencia del dualismo gnóstico. 22. ed., Castañeda, Buenos Aires, 1978, pp. 146-147.
} 
ha ocurrido en este mundo al momento de recibir la Gnosis. El banquete nupcial en la Ogdóada y el ingreso al seno de Dios para la boda espiritual con el ángel, representan la distinción entre la salus animae en la Ogdóada y la salus spiritus en el Pléroma, sin quitar ni agregar nada a la comunión perfecta del "espiritual" con Dios, lograda en este mundo desde el instante de su Gnosis. Sin embargo, no es creible que ya desde su situación terrenal los "espirituales" comprendieran al Padre y al Hijo en su perfección, y que la syntéleia sólo les otorgara la perfecta autonomía como puro pneuma, pues, satisfechos con creerse impecables y más allá de toda pasión, postergarían el conocimiento intuitivo de Dios y su comunión de vida con él, para el tránsito final a la syntéleia divina ${ }^{8}$. De este modo, la Gnosis no ganaría en perfección cuantitativa ni cualitativa con la syntéleia. En tal sentido, la segunda explicación resulta más plausible que la anterior, pues, aunque también sostiene que el hombre "espiritual" se salva radicalmente con la Gnosis ya aquí en este mundo, y se apropia de la Ciencia del ángel cuya suerte comparte, de tal manera que la Gnosis lo habilita para comulgar con el Espíritu del Padre y del Hijo, no obstante, el proceso recién se completa en la syntéleia final.

La diferencia entre ambas explicaciones radica entonces en el momento en que se le asigna al gnóstico la comunión perfecta del "espiritual" con Dios; la primera la considera lograda ya en su condición terrenal, mientras la segunda la posterga a una consumación en la syntéleia. Resulta curioso que el eclesiástico Clemente de Alejandría, buen conocedor de la doctrina valentiniana, se incline hacia la primera explicación, como parece sugerirlo al considerar al gnóstico dotado de una perfección desprovista de pasiones tales como el enojo, el deseo y el dolor?.

Habiendo expuesto con cierto detenimiento el proceso al que es sometido el hombre pneumático, podemos concluir que no resulta viable

8 Para el tema del "matrimonio espiritual" en los discípulos de Valentín, véase: Orbe Antonio, Op.cit., cap. 11, "El matrimonio espiritual"; pp. 279-297, y del mismo autor, "Los valentinianos y el matrimonio epiritual", en Gregorianum 58, Universidad Gregoriana, Roma, 1977, pp. 5-50.

9 "Ipse autem prorsus passionis erat expers, ut quem nullus subiret motus affectionis neque voluptas neque dolor" (Strómata VI,9,71). Citado en Roüet De Journel M.J., Encbiridion patristicum, 17ª.ed., Herder, Barcelona, 1951, p. 157. 
atribuirle una condición propiamente histórica. En primer lugar, porque su suerte se determina antes de la historia, en la interioridad del ser divino, y se consuma fuera de la historia, en el reingreso al Pléroma. Sólo una etapa de su vida está expuesta a la dramaticidad propia de la existencia dentro de los límites del tiempo y del espacio, y es la que media entre su aparición en este mundo como pneuma femenino imperfecto, y el momento repentino de la recepción de la Gnosis.

Además, en esta concepción la historia de la salvación ya no es el resultado de las opciones libres y responsables de los hombres, sino el mero despliegue de un designio incognoscible gestado en la intimidad inaccesible del ser divino, del cual ni aun el beneficiario es consciente.

Queda también en evidencia una contradicción interna magistralmente denunciada por Ireneo: la salvación o condenación está supeditada a las leyes de la sustancia, sea ésta pneuma, psyché o bylé, con lo cual resultan inútiles las acciones justas y meritorias; de este modo, ningún hombre puede superar el determinismo ontológico de su sustancia. Veamos cómo lo expone Ireneo:

"Dicen que en la consumación de los tiempos su Madre volverá a entrar en el Pléroma y recibirá como esposo al salvador, y que ellos, como son pneumáticos, una vez despojados de las almas y transformados en puras inteligencias espirituales serán dados como esposas a los Ángeles pneumáticos; pero que, como el demiurgo es psíquico, tomará el puesto de la Madre, y las almas de los justos tendrán reposo psíquico en la Región Intermedia. La razón que aducen es que los seres pneumáticos deberán reunirse con los pneumáticos y las almas deberán quedarse con las almas. Diciendo esto, se contradicen a sí mismos, porque no afirman que las almas irán a la región Intermedia para estar con sus semejantes, sino por sus obras, pues dan como razón que esto les sucederá por ser justas, mientras que los impíos se irán al fuego. Porque, si todas las almas debieran ir al descanso de la Región Intermedia por razón de su naturaleza, entonces tendrían que estar ahí todas las almas, siendo igual su naturaleza; pero entonces sería superfluo creer, porque también sería superfluo el descenso del Salvador. Y si van ahí por ser justas, entonces lo harán no por ser almas, sino por ser justas. Ahora bien, si las almas estaban destinadas a perecer si no se hiciesen justas, entonces la justicia igualmente puede salvar los cuerpos: ¿por qué no habría de salvarlos, si también ellos participaron de la justicia? Pero si es la naturaleza y la sustancia lo que salva, entonces se salvarán todas las almas; pero si lo que salva son la fe y la justicia, ¿por qué no pueden salvarse también los cuerpos, que habrian estado destinados a 
corromperse junto con las almas? Siendo así, su justicia es claramente impotente o injusta, si a unos salva porque participaron en ella y a otros no"10.

En este texto queda muy bien planteada la ambivalencia del destino que, según los valentinianos, fue trazado a partir de las cualidades de la sustancia, por un lado, y de las obras justas, por otro. Si los pneumáticos se salvan en virtud de la peculiaridad de su sustancia, en vano resultan la fe y las obras de justicia; y si los býlicos se pierden irremediablemente y están condenados a arder eternamente en las regiones inferiores, también se vuelve inútil la participación de los cuerpos en las obras de justicia.

No hay lugar para la ética ni para la esperanza, excepto en lo que atañe al hombre "psíquico", única especie en la cual los gnósticos admitían la posibilidad de actos libres y responsables.

\section{Ireneo: la unicidad del linaje humano}

Rechazando la fragmentación antropológica que proponen los valentinianos al afirmar que la especie humana está dividida en tres clases de hombres, Ireneo trata la tricotomía paulina caracterizada por cuerpo, alma y espíritu $^{11}$, no como tres hombres diversos, sino como tres componentes de un solo hombre.

Al mismo tiempo que toma distancia del proceso hacia la perfección trazado por los discípulos de Valentín para el hombre "espiritual", como un tránsito del pneuma femenino de Sophía al Pneuma masculino del Salvador, se aleja también de la concepción de Orígenes, de raíz filoniana-alejandrina, que considera el proceso hacia la teleiosis como el tránsito del hombre psyché u hombre nồs al hombre pneuma. En contraste con ambas escuelas, el Obispo de Lyon pondrá el centro de gravedad en el hombre sôma, y el proceso de deificación estará dado por el paso de la carne al espíritu, de la sarx al pneuma.

Precisamente en este punto descansa la revolución de Ireneo en favor del realismo antropológico, a saber, en que la Economía de deificación humana tiene como sustrato el cuerpo, la carne propiamente dicha. Según esta

\footnotetext{
10 Adv. baer: II,29,1. La discusión se prolonga hasta el 29,4.

11 I Tesalonicenses 5,23.
} 
antropología, el proceso deificante no afecta por igual a los tres componentes del hombre: a) no atañe al espíritu, ya que éste es lo que en el hombre activamente deifica, y no lo pasivamente deificado. El Salvador infunde su espíritu en el individuo en mayor o menor grado, pero no puede "espiritualizar" el espíritu, sino sólo la psyché y, fundamentalmente, el plasma del individuo; b) por ende, ese proceso afecta a la psyché conduciéndola a realizar actos racionales y libres emanados de ella, así como actos espirituales inspirados por el Espíritu; estos actos, precisamente por provenir de los impulsos del Espíritu, están revestidos de una dignidad divina. La docilidad de la psyché racional y libre a la guía del Espíritu, marca el ritmo de crecimiento o augmentum del proceso de deificación; c) pero sin ninguna duda, afecta principalmente al cuerpo, porque Dios sólo plasmó el cuerpo a imagen y semejanza suya. De modo que el proceso de deificación se regirá por las leyes del cuerpo humano; no depende de que la creatura "deificable" sea "espíritu", como enseñan los valentinianos, o psyché, como pretenden los origeneanos, sino que la cuestión radica en el curso que seguirá el cuerpo del hombre en las "Manos de Dios"12 para asimilar la imagen y semejanza divinas. Es el periplo desde el plasma primordial al plasma Pneuma, el tránsito del barro a Dios. A esto se refiere la feliz expresión de Orbe: "la cosa está en la creatura"13.

Con ello, Ireneo va contra la espontánea deificación del hombre "espiritual" de los gnósticos, que lo exime de las contingencias históricas de un desarrollo hacia su perfeccionamiento; sin resignarse a ser propiamente "hombres", pretenden tomar por una especie de "atajo ontológico" sin avenirse a la ardua disciplina del crecimiento. Presumen ser hijos naturales de Dios desde el principio, invocando una filiación superior que los convierte en una suerte de élite espiritual, a la vez que condenan a los llamados "hombres býlicos" a una marginación absurda de los beneficios que podría otorgarles la Economía salvífica, por considerarlos "hijos de las tinieblas"

12 Con esta expresión tomada de las Escrituras (Job 10,8; Sal.8,7; 119,73; Sab.3,1), Ireneo se refiere siempre al Hijo y al Espíritu Santo, las Manu Dei con las cuales el Padre creó el mundo y plasmó al hombre. Se repite en varias partes de su obra: $A d v$. baer.IV, Praef. 4; V,1,3; 5,1; 6,1; Epideixis 11.

13 Orbe Antonio, "Deus facit, bomo fit: un axioma de San Ireneo", en: Gregorianum 69, 4, Universidad Gregoriana, Roma, 1988, pp. 629-661. 
destinados a la muerte y condenación irremediables. Sólo los hombres psíquicos escapan de semejante determinismo por el cual se es hijo de Dios o hijo del diablo por naturaleza, sin la mediación de la responsabilidad humana.

Contrariamente a esto, la antropología de Ireneo afirma que todos los ángeles y hombres, sin excepción, son racionales y libres, creaturas del Dios Yabweh. Todos los hombres somos del mismo linaje, hijos positivos del Creador, y de ninguna manera hijos naturales ni positivos de un presunto Dios Bueno ${ }^{14}$. Asimismo, ofrece una explicación a la problemática expresión de las Escrituras "hijos del maligno", pero no en clave valentiniana, sino de acuerdo con la tradición de la Iglesia:

'Y como Dios creó todas las cosas, pero el diablo se convirtió en causa de la apostasía propia y de los otros, con justicia la Escritura a quienes perseveran en la apostasía siempre los llama "hijos del diablo" y "ángeles del maligno". Según hemos explicado anteriormente, de dos maneras se puede llamar "hijo" a una persona: o por naturaleza, en cuanto que es hijo de nacimiento, o porque se le hace hijo y se le tiene por tal. $Y$ hay diferencia entre nacer y hacerse: porque el primero nace de otro; en cambio el segundo es hecho por otro, es decir, o en cuanto a su ser o en cuanto a la enseñanza doctrinal ${ }^{15}$; pues suele llamarse hijo de un maestro a quien éste educa con su palabra, y al maestro se le llama padre. En cambio, por naturaleza todos somos hijos de Dios por la creación, pues Él nos ha hecho. Mas en cuanto a la obediencia y la doctrina, no todos son hijos de Dios, sino los que creen en Él (Jn.1,12) y hacen su voluntad (Mt.12,50). Quienes no creen ni hacen su voluntad son hijos y ángeles del diablo, porque hacen la voluntad del diablo $(\mathrm{n} n .8,41,44)$. Por eso dice Isaías: 'Hijos crié y elevé, pero ellos me despreciaron' (Is.1,2). Y también los llama hijos de extraños: 'Estos hijos extranjeros me engañaron' (Sal.18,46). Por naturaleza son sus hijos, porque Él los hizo; pero por sus obras no son sus hijos"16.

En estas líneas se perfila la doctrina de la filiación según Ireneo, que podemos resumir de la siguiente manera: el término "hijo" puede ser entendido de dos modos distintos: a) por naturaleza (secundum naturam), por

${ }^{14}$ Cfr. Plotino, Enneada (Enn.) II, 9,16: “Toda alma (es hija) de aquel Padre (psycbè dè pâsa patròs ekeinou)".

${ }^{15}$ En la antigüedad era común llamar "padres" a los maestros.

${ }^{16}$ Adv. haer. IV,41,2. 
haber nacido de la sustancia de un padre; b) por bechura (secundum id quod factus est), aunque nacido de alguien, ahijado por otro, becho bijo por otro, a título "positivo". A su vez, Ireneo subdivide en dos esta especie de filiación: $b_{1}$ ) por creación (secundum conditionem), tanto hombres como ángeles son hijos del Demiurgo Yabweh. La creación es el fundamento y principio de la naturaleza, y en ella se basa el título "positivo" de la filiación por bechura, b2 ) por doctrina o magisterio (secundum doctrinae magisterium), por la cual un discípulo se hace "hijo" de su maestro. Ambos títulos, creación y doctrina, se fundan en Gén.1,12: "Hagamos (poiesis) al hombre a nuestra imagen y semejanza". Aquellos que son hijos naturales del creador por haber sido bechos por Él, son llamados a asemejarse a Él, por el seguimiento y asentimiento de la fe a la doctrina y al "querer" (thélema) de Dios. Por su parte, los que lo rechazan y le desobedecen, se convierten en "hijos del diablo" por someterse a la "concupiscencia" (epithymia) del maligno ${ }^{17}$.

17 Según el valentiniano Heracleón, en una exégesis de Jn.8,44 que se conserva en sus fragmentos In Jobannem citados por Orígenes y probablemente conocidos por Ireneo, el diablo no tiene "querer" (thélema), pues éste es propio de Dios, sino "malos deseos" (epithymia). Esta distinción, rechazada por Orígenes y aceptada por Clemente de Alejandría, puede equipararse a la que hacen los estoicos entre boulésis y epithymía. Heracleón distingue tres especies de hijos: a) naturales: por generación; b) opcionales (gnóme): por sujetarse libremente a los dictámenes de aquel a quien siguen como padre; c) meritorios (axia): o por dignidad, quienes por imitación (mimesis) de ciertas obras merecen formar parte de la familia de aquellos de quienes se dicen hijos. Distingue entre los "hijos naturales" del diablo y los "hijos positivos" del diablo. En los primeros impera la naturaleza, mientras que en los segundos, el libre albedrío del hombre psíquico que, en vez de inclinarse al télema de Dios se dejó seducir por la epithymía diabólica. Según este autor, los judíos adversarios de Jesús son a la vez hijos "naturales" del Demiurgo Yabweh e hijos "opcionales" del diablo. Como consecuencia de la unión de su naturaleza psíquica racional con la libre inclinación hacia la concupiscencia diabólica, se hicieron hijos "meritorios" (o por "dignidad") de las tinieblas. Lo que los ángeles malignos y los hombres bjilicos hacen por naturaleza, sin culpa, los hijos naturales del Demiurgo lo hacen con culpabilidad manifiesta, en virtud de su libre opción por la epithymia del maligno.

Para conocer con mayores detalles la doctrina valentiniana de los géneros y especies de filiación, recomendamos el trabajo de Orbe Antonio. "¿San Ireneo adopcionista? 
A los que denomina "hijos de Dios" según doctrina o magisterio en Adv. baer. IV,41,2, los llama Ireneo "espirituales" en V,8,1s. y V,10,1s., y presenta el tema en la metáfora paulina de las "arras" del Espíritu, o anticipo de la gloria para quienes le obedecen:

"Ahora recibimos alguna parte de su Espíritu, para perfeccionar y preparar la incorrupción, acostumbrándonos poco a poco a comprender y a portar a Dios. El Apóstol lo llamó prenda (arras) -es decir, parte de la gloria que Dios nos ha prometido-, cuando dijo en la Epístola a los Efesios: 'En Él también vosotros, escuchada la palabra de la verdad, el Evangelio de vuestra salvación, creyendo en Él habéis sido sellados con el Espíritu Santo de la Promesa, que es prenda de nuestra herencia' (Ef.1,13-14). Por ello esta prenda, al habitar en nosotros, ya nos hace espirituales, y la mortalidad es absorbida por la inmortalidad (2Cor.5,4), pues dice: 'Vosotros no estáis en la carne, sino en el Espíritu, si el Espíritu de Dios habita en vosotros' (Rom.8,9). Esto no nos sucede por la destrucción de la carne, sino por la comunión del Espíritu; pues aquellos a quienes escribía no vivían sin la carne, sino que habían recibido el Espíritu de Dios, 'en el cual clamamos: '¡Abbá, Padre!' (Rom.8,15). Por ello, a quienes tienen la prenda del espíritu y no sirven a las concupiscencias de la carne, sino que se someten a sí mismos al Espíritu y se comportan según la razón en todas las cosas, justamente el Apóstol los llama espirituales; porque el Espíritu de Dios habita en ellos. En efecto, los espíritus incorpóreos no pueden ser hombres espirituales; sino que es nuestra sustancia, esto es, la unión de alma y carne, la que asume al Espíritu de Dios, y hace al hombre espiritual y perfecto" (Adv. haer. V,8,1-2).

Como puede apreciarse, estamos muy lejos del hombre "espiritual" de los gnósticos. En la concepción ireneana no es la sustancia, sino la cualidad del Espíritu que opera sobre la sarx que se somete a Dios, lo que hace a un hombre "espiritual".

Quedan así salvadas la libertad y responsabilidad humanas, frente a la tiranía de la sustancia que, según los gnósticos, decidía el destino eterno de los hombres.

En torno a $A d v$. haer. III,19,1", en Gregorianum 65/1, Universidad Gregoriana, Roma, 1983, pp. 5-52. 


\section{Consideraciones finales}

Al privilegiar una clase de hombres sobre otra invocando una naturaleza superior, los gnósticos promovieron una especie de "aristocracia espiritual" situada más allá de la responsabilidad que emana de las decisiones libres. Sólo para el hombre "psíquico" o "intermedio" entre el pneuma y la bylé admitían una condición histórica jalonada por las acciones libres y racionales. Lo que Ireneo afirma sobre todo hombre, ellos lo suscribían sólo para el hombre psyché. Pero la libertad que, según ellos, operaba en esta clase de hombre, no superaba el umbral de lo meramente racional, y lo calificaban de "libre albedrío" o autexousía, muy inferior a la libertad de la que gozaban los hombres "espirituales", que estaba más allá de los sentidos: la eleutbería o libertad de espíritu, de la cual su poseedor no era consciente. Se daba entonces la paradoja de una libertad sin libertad, de carácter suprarracional, impuesta por la Gnosis al momento de la Iluminación sin que medie la decisión del receptor, tanto para aceptarla como para resistirla. Se trata de una libertad necesaria, que sigue las leyes del Espíritu más allá del comportamiento de su poseedor.

Ireneo denuncia el caso de algunos que, valiéndose de este falso orgullo espiritual, lo utilizaron para encubrir toda suerte de desórdenes morales:

“Algunos de sus discípulos (de Marco, el mago), cometiendo los mismos errores han seducido a muchas mujerzuelas para corromperlas. A sí mismos se llaman los 'perfectos', pues imaginan que nadie puede igualar la grandeza de su gnosis; así fuesen Pablo o Pedro o cualquiera de los otros Apóstoles; porque saben más que cualquiera, pues únicamente ellos han bebido la grandeza de la gnosis de la Potencia inefable. Dicen estar en lugar más elevado que cualquier Potencia; por eso pueden libremente hacer lo que les plazca, sin temer nada ni a nadie" 18 .

En otro pasaje de su obra, el Lugdunense los ridiculiza con fina ironía, comparando su gesto grave y afectado y su pretendida superioridad religiosa con la "ostentación de un gallo", y definiendo a esta clase sectaria de individuo como "el hombre que viene de lo alto":

${ }_{18}$ Adv. haer. I,13,6. 
"Mas si alguno de entre sus oyentes le pide razones o los contradice, lo ridiculizan como quien 'no entiende la verdad ni ha recibido de las regiones superiores el semen de su Madre'; en suma, nada le responden, con el pretexto de que 'pertenecen al estadio intermedio', o sea a los 'psíquicos'. En cambio, si alguno como una ovejita se les entrega para imitarlos y recibir de ellos la 'redención', de tal manera se infla que llega a imaginar que no pertenece ya ni al cielo ni a la tierra, por haber ingresado al Pléroma y 'abrazado a su Ángel'. Desde entonces, camina con la cabeza erguida, mirando desde arriba, con la ostentación de un gallo. También hay entre ellos quienes enseñan que es necesaria una buena conducta para alcanzar al 'hombre que viene de lo alto'. Por eso fingen una seriedad afectada. Muchos de ellos desprecian a los demás porque ya pertenecen a los 'perfectos'. Viven sin respetar a los demás, teniéndolos en menos, pues a sí mismos se llaman 'espirituales', y presumen haber logrado ya conocer al que vive en el Pléroma, que es su lugar de refrigerio"19.

Tampoco Plotino escapó del asombro que causa semejante soberbia:

"Pero los hombres sin inteligencia, apenas oy'en decir: 'tú serás mejor que todos, no sólo que todos los hombres, sino aun que todos los dioses', inmediatamente dan crédito a tales palabras - el engreimiento abunda entre los hombres $-y$ aun el que antes era un individuo humilde, modesto $y$ corriente, se lo creen si le dicen: 'tú eres hijo de Dios, pero los otros, a los que admirábais, no lo son, ni lo son los seres que la gente venera por tradición de padres a hijos"'20.

Tanto en estas líneas como en las precedentes de Ireneo, se encuentran magníficamente descriptos los rasgos de la conducta sectaria que advertimos incluso en nuestros días en todos aquellos ámbitos en los que prolifera una religiosidad de élite, tanto en los nuevos movimientos religiosos como en vastos grupos dentro de las grandes religiones históricas, en los que se vislumbra un sentido de pertenencia a una casta de "salvados". Esto constituye una prueba de la pervivencia de la gnosis, y de la "religión de los escribas y fariseos" contra la que luchó Jesús de Nazaret.

Al afirmar que el hombre no puede hacerse Dios espontáneamente, sino que debe someterse a un largo proceso de crecimiento y disciplina que

\footnotetext{
19 Adv. haer. III,15,2.

${ }^{20}$ Enn. II,9,9.
} 
suele describir como "el lento acostumbrarse del Espíritu a morar en la carne" 21 , para "comprender y portar a Dios"22, Ireneo devuelve al hombre al corazón de la historia, de donde la repentina centella de la gnosis lo había sacado; lo confronta con sus decisiones libres y su propia responsabilidad, haciéndolo artífice de su propio destino y arrancándolo de las garras del fatalismo cósmico que, según los gnósticos, lo había encadenado a la naturaleza de su sustancia.

La imagen divina en el hombre no se adquiere a la manera de los gnósticos, en un instante privilegiado que patentiza una arbitraria elección de Dios, sino a lo largo de un proceso de "hominización" que Ireneo llama androzénai, "hacerse hombre":

“¿Cómo podrías hacerte Dios, si primero no te haces hombre? ¿Cómo pretendes ser perfecto, si fuiste creado en el tiempo? ¿Cómo sueñas con ser inmortal, si en tu naturaleza mortal no has obedecido a tu Hacedor? Es pues necesario que primero observes tu orden humano, para que en seguida participes de la gloria de Dios"23.

Este proceso dinamiza la imagen divina en el hombre, el que una vez creado, debe crecer en un proceso hacia la teleiosis al que Ireneo no llama "evolución", sino "maduración" 24 , atendiendo al reconocimiento por parte del hombre de su creaturidad concreta, en una historia que es la historia misma de la libertad, en la que el hombre al crecer se hace adulto, se hace comunidad y multiplica las fuerzas de la comunidad para pasar desde allí a la gloria que Pablo llama "la libertad gloriosa de los hijos de Dios" (Rom.8,21), y compartir en ella misma la vida de Dios, es decir, "verlo".

Esta visio es la libertad en el final de su cauce, la libertad consumada en su carácter escatológico. De ahí la superioridad cualitativa del "proceso" sobre el "instante mágico", de la sarx disciplinada hacia el pneuma, sobre el pneuma instantáneo sembrado en la sarx, del hombre histórico sobre "el hombre que viene de lo alto".

\footnotetext{
21 Adv. haer. III,17,1.

22 Adv. haer. V,8,1.

${ }_{23}$ Adv. haer. IV ,39,2.

${ }_{24}$ Adv. haer. IV,5,1.
} 
El "hombre que viene de lo alto" - 43

\title{
Resumen
}

Los gnósticos del S. II proponían una concepción diferenciada de "hombre" haciéndola depender de la sustancia que en cada caso lo constituía. Bajo esta distinción de naturalezas subyacía una cosmología sustentada en un mito colosal. La diversidad de sustancias determinaba una variedad de especies de hombres cuya dignidad variaba desde lo más sublime a lo más bajo, desde los "elegidos" a los "réprobos", pasando por un nivel intermedio, equidistante de ambos. Dentro de las distintas familias gnósticas, la de los valentinianos se destacó, entre otras cosas, por la meticulosa descripción del mito fundacional de semejante antropología. De esta concepción surgió una antropología fragmentada, que suscitó el problema de la condición histórica de cada uno de los linajes humanos resultantes, así como también la cuestión de la libertad. La coherencia de esta doctrina exigió la creación inevitable de una especie de "ghetto" espiritual en el cual colocaban a una de las especies humanas, al mismo tiempo que confinaban a otra a la marginalidad antropológica, relegando la libertad y conciencia histórica a la especie intermedia de hombres. La reacción de la Iglesia cristiana encontró su adalid en Ireneo de Lyon, quien impugnó esa antropología de exclusión afirmando la unicidad del linaje humano y la condición libre y dramática en la historia de todos los hombres sin excepción.

Palabras claves: "gnosticismo", "antropología", "Ireneo de Lyon”.

\begin{abstract}
The Gnostics of the II century proposed a differentiated conception of the "man", making it dependent on the substance that in every case was his constituent. Under this distinction of natures underlie a cosmology sustained in a colossal myth. The diversity of substances determined a variety of men's species which dignity changed from the most sublime to the lowest level, from the "chosen ones" to the "reprobates", passing for a intermediate level, equidistant of both. Inside the different gnostic families, that of the valentinians was conspicuous, among other things, for the meticulous description of the foundational myth of such anthropology. From this conception arose a fragmented anthropology, which provoked the problem of the historical condition of each human resultant lineages, as well as the question of freedom. The coherence of this doctrine demanded the inevitable creation of a type of spiritual "ghetto" in which they placed one of the human species while at the same time they confined another to an anthropological marginality, relegating feedom and historical consciousness to the intermediate species of men. The reaction of the Christian Church found a leader in Irineo of Lyon, who refuted that anthropology of exclusion claiming the unicity of the human
\end{abstract}


44 - Juan Carlos Alby

lineage and the dramatic and free condition of all men without exception in the history.

Key' words: "gnosticism”, “ anthropology", "Ireneus of Lyon”. 